\title{
More than poverty: disruptive events among women having abortions in the USA
}

\author{
Rachel K Jones, ${ }^{1}$ Lori Frohwirth, ${ }^{2}$ Ann M Moore ${ }^{3}$
}

\begin{abstract}
${ }^{1}$ Senior Research Associate, Guttmacher Institute, New York, NY, USA

${ }^{2}$ Research Associate, Guttmacher Institute, New York, NY, USA ${ }^{3}$ Senior Research Associate, Guttmacher Institute, New York, NY, USA
\end{abstract}

\section{Correspondence to} Dr Rachel $\mathrm{K}$ Jones, Guttmacher Institute, 125 Maiden Lane, 7th Floor, New York, NY 10038, USA; rjones@guttmacher.org

Received 23 January 2012 Revised 21 March 2012 Accepted 6 April 2012 Published Online First 21 July 2012
To cite: Jones RK, Frohwirth L, Moore AM. Journal of Family Planning and Reproductive Health Care 2013, 39, 36-43.

\begin{abstract}
Background In the USA, abortion has become increasingly concentrated among poor women. For many, poverty represents difficulties meeting financial obligations, but the authors expect it is also associated with a range of potentially difficult life circumstances that may influence women's pregnancy decisions.
\end{abstract}

Methods This mixed methods study relied on two data sources. Quantitative data came from a national sample of 9493 women obtaining abortions in 2008 and examined exposure to 11 potentially disruptive events. The authors also examined associations between disruptive events, poverty status and contraceptive use. Qualitative information from 49 in-depth interviews was used to provide insights into patterns that emerged from the quantitative analysis.

Results More than half (57\%) of the women obtaining abortions experienced a potentially disruptive event within the last year, most commonly unemployment (20\%), separation from a partner (16\%), falling behind on rent/ mortgage (14\%) and/or moving multiple times (12\%). Poverty status was significantly associated with several of the events, particularly those that could directly impact on a family's economic circumstances, for example losing a job or having a baby. Information from the in-depth interviews suggested that disruptive events interfered with contraceptive use, but the quantitative survey found no difference in contraceptive use by exposure to disruptive life events, even after controlling for poverty status.

Conclusion Many abortion patients make decisions about their pregnancies in the midst of complex life circumstances.

\section{BACKGROUND}

Women have abortions for a myriad of reasons. Just under three-quarters of abortion patients in the USA in 2004 indicated that having a child would interfere with their school, employment or

\section{Key message points}

- Most women who have abortions in the USA have experienced one or more disruptive events in the past year, and exposure to these events is more common among women with poverty level incomes.

- Many abortion patients in the USA make decisions about their pregnancies in the midst of complex life circumstances.

ability to care for other dependents, and a similar proportion related that they could not currently afford a child. ${ }^{1}$ Most women identified multiple reasons for their abortions, and this same study found that nearly half $(48 \%)$ of women seeking abortions did not want to be a single mother, or were having relationship problems, and smaller proportions cited disruptive situations such as unemployment (their own, 22\%, or their partners', 12\%) and housing instability $(19 \%)$ as contributing to their decision. Thus, the most common reasons why women seek abortions are to avoid disrupting their lives, but many also do so in response to disruptive events that have already occurred.

In 2008, a family of three with an annual pre-tax income of US\$17 600 or less was considered poor, and $13 \%$ of USA residents met this criterion. ${ }^{2}$ Poor women are over-represented among abortion patients, and this has been increasing over time. Abortions among poor women accounted for $42 \%$ of the 1.21 million procedures performed in 2008, up from $27 \%$ of 1.31 million abortions performed in $2000 .^{3}$ Poverty can represent difficulties meeting financial obligations such as paying rent and buying food, but the circumstances faced by poor women may extend beyond these types of financial 
difficulties. For example, poor women have less stable relationships ${ }^{4}$ and reduced access to health care. ${ }^{6}$ These situations can increase both the risk of unintended pregnancy and women's motivations to terminate them.

Nationally, slightly more than $1 \%$ of women were exposed to sexual or physical violence by an intimate partner in the last 12 months. $^{7}$ Some $7 \%$ of all women obtaining abortions in 2008 reported that they had ever been physically or sexually abused by the man with whom they became pregnant, ${ }^{8}$ suggesting that women with abusive partners are substantially over-represented among abortion patients. Intimate partner violence (IPV) can serve as a distinct form of disruption. While employment and separation from a partner occur infrequently, IPV can be recurrent. Women living in poverty are disproportionately represented among women experiencing IPV, ${ }^{9}$ but whether IPV is more prevalent among poor women obtaining abortions has not been previously explored.

Poverty can also impact on contraceptive use patterns. Disadvantaged women are less likely to use contraception and more likely to have gaps in use than are better-off women, ${ }^{10}$ and poor women are more likely than better-off women to experience contraceptive failures. ${ }^{11}$ Among abortion patients in $2000,48 \%$ of those living below the poverty line were using a contraceptive method in the month that they became pregnant compared to $60 \%$ of women at $300 \%$ of poverty or higher. ${ }^{12}$ If poor women experience more disruptions in their lives, this could interfere with their ability to consistently use contraception and, in turn, contribute to their higher levels of unintended pregnancy and abortion. ${ }^{13}$

Picking up where previous analyses have left off, this article addresses several gaps. The extent to which a national sample of women obtaining abortions experienced a range of potentially disruptive events in the 12 months prior to the abortion is examined with a view to determining whether these experiences differ according to poverty status. The study also aimed to assess whether exposure to IPV is more common among poor women obtaining abortions. Lastly, this article explores associations between contraceptive use, poverty and disruptive events, as the authors expect that experiences such as unemployment and having a child could interfere with the ability of women to access and use contraception.

\section{METHODS}

\section{Data}

The 2008 Abortion Patient Survey (APS) is the fourth in a series and uses a design and questionnaire similar to those for studies of abortion patients conducted in 1987, 1994-1995 and 2000-2001. A sample of facilities providing abortion services was randomly selected from all hospitals, clinics and physicians' offices where abortions were known to be performed in 2005. Staff members distributed an anonymous, four-page questionnaire to all women who obtained an abortion during the fielding period (which ranged from 2 to 12 weeks). The survey header was a statement of informed consent, but signed consent was not obtained as the signatures would have been a source of identifying information. Participating facilities $(n=95)$ reported performing 12866 abortions during the fielding period, and the final sample contains information from 9493 women (a response rate of $74 \%)$. Missing information on key demographic variables was imputed, and weights were constructed to correct for non-response and to make the data representative of all women obtaining abortions in the USA. More detailed information about the data collection procedures has been published elsewhere. ${ }^{3} 814$

To complement the quantitative survey, the authors also conducted 49 semi-structured in-depth interviews (IDIs) with women aged 18 years or older between June and October 2008. One goal of the qualitative component was to explore abortion patients' expectations around abortion counselling, and the facilities were purposively selected to represent states with different state-mandated counselling requirements. The interviews took place at three clinics: one located in a large city in Texas (mandated counselling and a 24-hour waiting period), one in a mid-sized city in Connecticut (state-mandated information must be included in the informed consent materials) and one in a small city in Washington state (no state mandated regulations for counselling). Respondents were recruited by members of the interview team from the waiting rooms of the clinics. The interviews included questions about respondents' life circumstances, including factors that led them to decide to terminate this pregnancy. Oral consent was obtained from all qualitative participants, and each received US\$35 cash as compensation for her time. More detailed information about the qualitative data collection procedures is available in another publication. ${ }^{15}$ All survey procedures and study instruments were approved by the Institutional Review Board of the authors' institution.

\section{Key variables}

The quantitative survey assessed whether women had experienced 11 potentially disruptive events in the last 12 months (Table 1). Most of these 11 items were adopted from the General Social Survey (GSS), a biannual survey that collects information on attitudes and beliefs from a nationally representative sample of adults. The list was restricted to events the authors anticipated would be most common among abortion patients based on prior qualitative research. ${ }^{1} 16$ The authors' original intention was to compare exposure to events between all women of reproductive age (GSS) and women obtaining abortions, but the items were not asked on the 2008 version of the GSS survey. 
Table 1 Life disruptions and exposure to intimate partner violence among women obtaining abortions, by poverty status, 2008 Abortion Patient Survey

\begin{tabular}{|c|c|c|c|c|c|}
\hline \multirow{3}{*}{$\begin{array}{l}\text { Women's responses to question: } \\
\text { "In the last } 12 \text { months have you } \\
\text { experienced any of the following?" }\end{array}$} & \multirow{3}{*}{$\begin{array}{l}\text { All women } \\
(n=9493)\end{array}$} & \multicolumn{3}{|c|}{ Poverty status } & \multirow[b]{3}{*}{$p$} \\
\hline & & $<100 \%$ & $100-199 \%$ & $200+\%$ & \\
\hline & & $(n=3990)$ & $(n=2544)$ & $(n=2959)$ & \\
\hline $\begin{array}{l}\text { I was unemployed or looking for work for } \\
\text { at least a month }\end{array}$ & 19.9 & 25.3 & 18.8 & 13.6 & 0.000 \\
\hline I separated from my partner/husband & 16.2 & 17.3 & 16.9 & 14.0 & 0.013 \\
\hline I fell behind on my rent or mortgage & 14.4 & 16.0 & 16.0 & 11.0 & 0.000 \\
\hline I moved two or more times & 11.8 & 14.3 & 11.7 & 8.4 & 0.000 \\
\hline A close friend died & 10.2 & 10.8 & 10.0 & 9.5 & 0.274 \\
\hline I had a baby & 10.2 & 13.8 & 10.5 & 5.2 & 0.000 \\
\hline $\begin{array}{l}\text { A dependent/family member had a serious } \\
\text { health problem }\end{array}$ & 6.9 & 6.5 & 7.4 & 7.1 & 0.362 \\
\hline My partner was in jail or incarcerated & 5.7 & 7.0 & 5.9 & 3.7 & 0.000 \\
\hline I had a serious health problem & 3.2 & 3.4 & 3.3 & 3.0 & 0.763 \\
\hline I was the victim of a robbery or assault & 1.6 & 1.8 & 1.6 & 1.3 & 0.266 \\
\hline My home was burglarised & 1.5 & 1.6 & 1.7 & 1.2 & 0.340 \\
\hline \multicolumn{6}{|l|}{ Number of events } \\
\hline One or more & 57.4 & 62.8 & 58.8 & 48.9 & 0.000 \\
\hline Two or more & 25.4 & 29.9 & 26.1 & 18.5 & 0.000 \\
\hline Three or more & 11.2 & 14.6 & 11.2 & 6.5 & 0.000 \\
\hline \multicolumn{6}{|l|}{ Has the man who got you pregnant ever } \\
\hline $\begin{array}{l}\text { Hit, slapped, kicked or otherwise } \\
\text { physically hurt you? }\end{array}$ & 5.8 & 7.8 & 5.4 & 3.5 & 0.000 \\
\hline $\begin{array}{l}\text { Forced you to so something sexual } \\
\text { when you didn't want to? }\end{array}$ & 2.6 & 3.6 & 2.1 & 1.6 & 0.000 \\
\hline Either of the above? & 7.0 & 9.3 & 6.4 & 4.4 & 0.000 \\
\hline
\end{tabular}

In the quantitative survey, contraceptive use is based on a series of three items asking respondents the last method they used, how long they had been using it, and the month and year they had stopped. As in prior APS surveys, contraceptive use refers to use of any method during the month the woman got pregnant. ${ }^{12}$

Exposure to IPV was measured according to two items adopted from domestic violence screening instruments: ${ }^{17}$ "Has he [the man with whom you became pregnant] ever hit, slapped, kicked or otherwise physically hurt you?" and "Has he ever forced you to do anything sexual when you didn't want to?" Exposure to IPV was examined separately to other disruptive life events because the time frames were not comparable and because exposure to IPV is qualitatively different from other disruptive events.

The key independent variable of poverty was based on two items that asked about total family income in the last year and the number of people living in the household. The classifications for poverty status are poor (under $100 \%$ of the federal poverty line for family size), lowincome (100-199\%) and better-off (200\% or more).

\section{Analytical strategy}

For the quantitative analysis, percentage distributions were used to present incidence of disruptive life events. Chi-square $\left(\chi^{2}\right)$ statistics assessed statistically significant associations in the bivariate analyses. All analyses relied on weighted data and the complex sampling feature of Stata $12.0^{\mathrm{TM}}$ (StataCorp, College Station, TX, USA).

For the qualitative analysis, an inductive and deductive code structure was developed using NVivo $8^{\mathrm{TM}}$ (QSR International, Cambridge, MA, USA). Analyses were conducted to summarise themes and concepts. The relevant theme for this analysis was the ways that disruptive life events interact and overlap with one another, which the authors had not conceptualised at the start of the study. For the purposes of this analysis, the qualitative data were used to provide insights into the quantitative findings and to provide insights into events and contraceptive use dynamics that were absent from the quantitative component (unanticipated themes). For analyses relying solely on the qualitative data see Moore et al. ${ }^{15}$ 


\section{RESULTS}

\section{Patient demographics}

The demographic profile of women obtaining abortions in 2008 has been reported elsewhere, ${ }^{3}$ but Table 2 shows the characteristics of this population as well as the qualitative sample. The IDI sample was generally similar to abortion patients nationally with the exceptions that smaller proportions of qualitative respondents were Black (10\% vs 30\%) and poor $(29 \%$ vs $42 \%)$ women. Regarding the latter, the observation that $39 \%$ of the IDI sample is low-income suggests that, even if they were not poor, many still had financial difficulties.

\section{Disruptive events}

Women accessing abortion services experienced a range of disruptive events in the last 12 months (Table 1). Most commonly, they reported that they had been unemployed for at least a month (20\%), separated from a husband or partner (16\%), fallen behind on the rent or mortgage (14\%), and/or moved two or more times (12\%). Ten percent had experienced the death of a close friend or had had a baby in the past year.

Poverty status was associated with several of the events which, in most cases, were most commonly experienced by poor women. One-quarter $(25 \%)$ of poor women had been unemployed for at least a month compared to $14 \%$ of better-off women. A higher proportion of poor women had also separated from a partner, fallen behind on rent or mortgage, moved two or more times or had had a baby.

A majority of the IDI respondents had experienced one or more disruptions, and these events sometimes directly influenced their decision to have an abortion.

"I have two babies, so I have an 18-month and a 6-month old ... so I can't have another one right now. ... I just know I am not strong enough for it; some women are stronger than others. I am just not strong enough to take care of three kids. ... they both cry at the same time, and I am sick [from this pregnancy]. Ob no; I can't do it, I am sorry." [Poor, two children, married]

Another reported that she felt a great deal of responsibility to take care of both her own and her sister's family after the death of her mother.

"My mother just recently passed away. ... Right now would not be a good time to have to be able to take care of the baby .... Now I am the head of household. So I have to make sure everything that has to do with the house is under control." [Poor, one child, in a noncohabiting relationship]

Some IDI respondents also spoke about disruptive events that were not captured on the survey instrument, including a change in work status (e.g. working more or fewer hours), starting or stopping school, homelessness, drug use and getting sober. Partner
Table 2 Personal and relationship characteristics of women obtaining abortions, quantitative and qualitative sample, 2008 Abortion Patient Survey

\begin{tabular}{|c|c|c|}
\hline Characteristic & $\begin{array}{l}\text { Quantitative } \\
(\%)(n=9493)\end{array}$ & $\begin{array}{l}\text { Qualitative } \\
(\%)(n=49)\end{array}$ \\
\hline \multicolumn{3}{|l|}{ Age group (years) } \\
\hline$<17$ & 6.6 & 0.0 \\
\hline $18-19$ & 11.0 & 10.2 \\
\hline $20-24$ & 33.4 & 51.0 \\
\hline $25-29$ & 24.4 & 16.3 \\
\hline $30-34$ & 13.5 & 18.4 \\
\hline $35-39$ & 8.2 & 2.0 \\
\hline $40+$ & 2.9 & 2.0 \\
\hline \multicolumn{3}{|l|}{ Race and ethnicity } \\
\hline Non-Hispanic White & 36.1 & 46.9 \\
\hline Non-Hispanic Black & 29.6 & 10.2 \\
\hline Asian, South Asian, API & 6.7 & 4.1 \\
\hline Non-Hispanic other & 2.7 & 4.0 \\
\hline Hispanic & 24.9 & 34.7 \\
\hline \multicolumn{3}{|l|}{ Poverty status } \\
\hline$<100 \%$ & 42.4 & 28.6 \\
\hline $100-99 \%$ & 26.5 & 38.8 \\
\hline $200+\%$ & 31.1 & 32.7 \\
\hline \multicolumn{3}{|l|}{ Education } \\
\hline Less than 12 th grade & 18.3 & 8.2 \\
\hline High school graduate or GED & 29.5 & 14.3 \\
\hline Some college or associate degree & 35.8 & 63.3 \\
\hline College graduate or above & 16.5 & 14.3 \\
\hline \multicolumn{3}{|l|}{ Prior births } \\
\hline 0 & 39.1 & 49.0 \\
\hline 1 & 26.5 & 14.3 \\
\hline $2+$ & 34.5 & 36.7 \\
\hline \multicolumn{3}{|l|}{ Union status } \\
\hline Married & 14.8 & 22.4 \\
\hline Cohabiting & 29.2 & 22.4 \\
\hline Never married & 45.0 & NA \\
\hline Divorced or widowed & 5.3 & NA \\
\hline Separated from husband & 5.7 & NA \\
\hline
\end{tabular}

API, Asian Pacific Islander; GED, General Educational Development degree; $N A$, not available.

conflict that did not lead to separation could also be disruptive.

"Me and [my husband] are going through some problems right now, and I figure, what if I had to [do]) it by myself? I cannot, like, nowadays daycare cost... people charge you too much .... So I was just thinking about [having the baby], ...but right now my life is not good." [Poor, two children, married]

As in the quantitative survey, the IDI respondents with fewer financial resources appeared to be disproportionably affected by disruptive events. More often than women with higher incomes, they mentioned losing jobs, having to take on more responsibilities after separating from partners, experiencing deaths in their families and difficulties related to drug use. 
More than half $(57 \%)$ of the women in the quantitative survey had experienced at least one disruptive event during the past year (Table 1), and a higher proportion $(63 \%)$ of poor women did so compared to better-off women (49\%). One-quarter of patients had experienced two or more events and slightly more than one in 10 women $(11 \%)$ had experienced three or more. Incidence increased as income decreased. Most IDI respondents who reported disruptions related experiencing multiple disruptions within the past year, and the phrase "A lot was going on" was used by several respondents. In some cases, disruptive events were interrelated.

"Well, at the time [that I became pregnant] my boyfriend, ... we were good, things were stable between us. And then his mom had kicked us out of the house, so we were living out of a motel. We were going from motel to motel and ... he was trying to bring in money, because I was sick, I couldn't work: I [was] constantly throwing up. And then, I guess the pressure on him of taking care of me and knowing that I was pregnant got to him, and just all of a sudden, out of the blue, he said, 'Go your way, I will go my way. I have to take care of my own and you take care of your own'." [Poor, one child, not in a relationship]

Respondents described how the emotional impact of one disruption could lead to others. The emotional difficulty that one woman experienced after her mother died kept her from leaving an abusive partner.

"I mean, I was actually seeing a counsellor for depression. I was put on antidepressants and anxiety medications, and it just - I should have left before, and I just didn't. I mean, through therapy, through everything, I know I should have left sooner and, you know, my mom got sick all of a sudden [and subsequently died], and all this happened, so I just didn't get out when I should have." [Poor, two children, married]

\section{Intimate partner violence}

Associations between exposure to IPV and poverty status were statistically significant, and poor women were at least twice as likely to have been exposed to any type of IPV than were better-off women (Table 1).

A few of the qualitative respondents had been physically abused or sexually assaulted by their partners, and one had become pregnant as a result of sexual assault by a stranger. Their stories illustrate how IPV can act as a disruptive factor in women's lives.

"He's physically abusive ... I just feel like he is unstable right now, and, you know, I just don't think that - I see my kids [I already have] right now without a dad and I just, you know, I just don't want to do that [again]." [Poor, five children, not in a relationship]

"Well, actually, my situation - my husband was beating me. I fled. He raped me. And that's when I was [got] pregnant. So I want to terminate it and move on." [Poor, no children, married]

\section{Disrupted contraceptive use}

Nearly half of the interviewees reported that disruptive events had interfered with their contraceptive use. Hectic or inconsistent work schedules, holding down multiple jobs, and balancing work with childcare responsibilities made it difficult for some women to keep medical appointments to obtain hormonal contraception.

"You go and get them [Depo-Provera ${ }^{\circledR}$ shots] like every 3 months, and it had been, like, five, and I just took over a new business, and I am working, like, 90 hours a week. I mean, I am not making any money from my business, but I am working, like, you wouldn't imagine. So, I completely didn't even think about it." [Low-income, no children, cohabiting]

"I work 6 days a week, I am tired. I worked last night, a double shift, and I am here today and it's my only day off ... And when I am not working I am home with the kids. I am just always so beat that I just - I don't make it to places that I should make it to, like my appointment and stuff like that." [Low-income, two children, married]

Several women mentioned losing jobs, which led to loss of health insurance, and, in turn, loss of access to hormonal contraception. Others said that the cost of contraception, even through publicly funded health clinics, was more than they could afford at the time.

Another factor affecting some women's ability to prevent pregnancy was contraceptive sabotage. Six of the interviewees reported that they suspected or knew that their partners had tried to impregnate them against their will, usually by refusing to withdraw. One woman, who had two sons and whose husband wanted a daughter, reported that he had discouraged her from going back on the pill because he perceived it to have negative side effects. His refusal to withdraw, which had been their agreed-upon method of contraception, resulted in her current pregnancy.

Associations between contraceptive use and disruptions were less straightforward in the quantitative survey. Just over half $(51 \%)$ of abortion patients surveyed in the USA reported using a contraceptive method during the month they became pregnant (Table 3). Most commonly, $27 \%$ had been using condoms, $17 \%$ reported using a hormonal method, $6 \%$ had been relying on withdrawal and $2 \%$ were using some other method (data not shown). While contraceptive non-use and number of disruptions were statistically associated, there was no clear pattern. Levels of contraceptive use were highest for women who reported no disruptions or two disruptions $(52 \%$ and $53 \%$, respectively), but were not substantially different for women who reported one or three or more disruptions (49\%). 
Table 3 Contraceptive use in the month of pregnancy among abortion patients in the USA, by selected characteristics, 2008 Abortion Patient Survey

\begin{tabular}{|c|c|c|c|c|}
\hline \multirow[b]{3}{*}{ Characteristic } & \multirow{3}{*}{$\begin{array}{l}\text { All } \\
\text { women } \\
100.0 \\
(n=9493)\end{array}$} & \multicolumn{3}{|c|}{ Using contraception? } \\
\hline & & \multirow{2}{*}{$\begin{array}{l}\text { Yes } \\
51.0 \\
(n=4884)\end{array}$} & \multirow{2}{*}{$\begin{array}{l}\text { No } \\
49.0 \\
(n=4609)\end{array}$} & \multirow[b]{2}{*}{$p$} \\
\hline & & & & \\
\hline \multicolumn{4}{|c|}{ Number of events in last 12 months } & 0.026 \\
\hline 0 & 4013 & 51.9 & 48.1 & \\
\hline 1 & 3033 & 49.4 & 50.6 & \\
\hline 2 & 1359 & 53.3 & 46.7 & \\
\hline $3+$ & 1088 & 49.0 & 51.0 & \\
\hline \multicolumn{4}{|l|}{ Poverty status } & 0.000 \\
\hline $100 \%$ & 3998 & 44.4 & 55.6 & \\
\hline $100-199 \%$ & 2525 & 54.3 & 45.7 & \\
\hline $200+\%$ & 2970 & 57.2 & 42.8 & \\
\hline \multicolumn{5}{|c|}{ IPV: Has the man who got you pregnant ever } \\
\hline $\begin{array}{l}\text { Hit, slapped. kicked } \\
\text { or otherwise } \\
\text { physically hurt you? }\end{array}$ & 549 & 44.5 & 55.5 & 0.005 \\
\hline $\begin{array}{l}\text { Forced you to do } \\
\text { something sexual? }\end{array}$ & 243 & 56.2 & 43.8 & 0.147 \\
\hline Either of the above? & 659 & 46.1 & 53.9 & 0.023 \\
\hline No exposure to IPV & 8554 & 51.6 & 48.4 & 0.023 \\
\hline
\end{tabular}

Associations between poverty status and contraceptive use were statistically significant and easier to interpret. Some $44 \%$ of poor women reported using contraception the month they became pregnant compared to $54 \%$ and $57 \%$ of low-income and better-off women, respectively. Women exposed to physical, but not sexual, violence reported lower levels of contraceptive use in the month they got pregnant compared to those who had not experienced physical abuse (45\% compared to $52 \%$ ).

Because poor women experienced more disruptions and were less likely to be using contraception, the authors hypothesised that poverty status may be a confounder of the relationship between disruptions and non-use of contraception. Logistic regression was used to examine associations between these two variables after controlling for poverty status (data not shown) but, even after taking poverty status into account, women who experienced no disruptions were no more or less likely to report contraceptive use in the month they got pregnant than those who experienced one, two or three disruptions.

\section{DISCUSSION AND CONCLUSIONS}

The authors found that most women accessing abortion services in the USA had dealt with at least one disruptive event in the 12 months preceding the abortion. Information from the in-depth interviews revealed that some women were exposed to disruptive situations that were not assessed in the present quantitative survey. Thus, the true extent to which women having abortions have experienced disruptive events is likely to be higher than what was measured in the quantitative survey.

Women living below the federal poverty line are substantially over-represented among abortion patients. ${ }^{3}$ The authors' research suggests that in addition to economic hardship, poor women obtaining abortions are more likely than those who are betteroff to be dealing with disruptive events. That poor women were more likely to experience life events such as unemployment, breaking up with a partner, and having a baby may be both a cause and a consequence of economic strain. For example, having a newborn or becoming unemployed can directly impact the economic resources available to women and their families and move them into poverty. Conversely, couples with limited financial resources may be more likely to break up due, in part, to the strains caused by economic hardship.

One in four abortion patients had dealt with more than one disruption in the 12 months prior to the abortion, and information from the interviews revealed that disruptions could be interrelated. The quantitative data show that multiple disruptions were more common among abortion patients living in poverty, perhaps because a lack of financial resources prevents them from dealing with the fallout from one disruption and, in turn, a 'chain effect' is initiated.

About half of the abortion patients were using contraception in the month they got pregnant, and non-use of contraception was more common among poor women relative to those who were better-off. While the qualitative data suggest that disruptive events sometimes led to difficulties accessing or using contraception, the authors found no associations between disruptions and non-use of contraception in the quantitative sample, even after controlling for poverty status. There are several potential explanations for these seeming discrepancies. First, the quantitative survey measured contraceptive use during the month of pregnancy, but information from some of the IDI respondents suggested that the impact of the disruptions had begun several months prior to getting pregnant. Additionally, the measure in the quantitative survey may be too unrefined to capture the dynamics of contraceptive use. For example, some women may have been on the pill in the month they got pregnant, but taken it inconsistently due to disruptive events.

A small but non-negligible proportion of women obtaining abortions were exposed to IPV by the man with whom they got pregnant and this, too, was more common among poor women relative to those who were better-off. The qualitative data revealed that IPV can introduce instability into women's lives, and this may contribute to the association between IPV and reduced levels of contraceptive use found in the 
quantitative survey. The interviews also revealed instances of reproductive control where male partners engaged in birth control sabotage, though these were not necessarily associated with IPV.

This study has several potential limitations. The survey was conducted in the midst of a recession and outcomes such as unemployment may be experienced less frequently by abortion patients during more stable economic times. Alternately, it is unclear if abortion patients experienced disruptive events at the same, higher or lower level than all women. In 2008, $6 \%$ of women reported having a child in the last 12 months, ${ }^{18}$ and the unemployment rate for all women was $5.4 \% .{ }^{19}$ However, national data on most of the disruptive events assessed in the present study are not available, and it cannot be assumed that all of these events were also more common among abortion patients. Exposure to violence may be underreported, ${ }^{20}{ }^{21}$ and thus the measure of IPV exposure should be regarded as a conservative one. The present study is limited to women who were able to access abortion services; undoubtedly there are women, and poor women in particular, who were unable to do so. Finally, the present investigation is not meant to establish or imply causality. Rather, information about the number and type of disruptive events experienced by women who have abortions provides insights into the complexities of their lives and a better understanding of the context in which they make decisions about how to resolve their unintended pregnancies.

This research has several policy implications. It is possible that easier access to highly effective methods could reduce unintended pregnancy among women who experience disruptive events (e.g. if methods were available free of charge, over the counter, or if multiple refills could be obtained at one time). Increased access to long-acting contraceptive methods such as the intrauterine device could also reduce the ability of disruptive events to interfere with contraceptive use as these methods do not require refills or maintenance costs. Of note is that the IDIs revealed that some unintended pregnancies were the product of birth control sabotage and sexual violence. Clearly, women experiencing these events will have less control over pregnancy prevention. Screening for reproductive control by health care providers may provide useful information for women who are experiencing these forms of abuse and help determine an appropriate contraceptive method for them.

Acknowledgements The authors would like to acknowledge Lawrence B Finer and Heather Boonstra for their helpful commentary on drafts of this paper, Kathryn Kooistra, Luciana Hebert, Allison Gemmill, Kathryn Stewart, Alyssa Tartaglione, Nakeisha Blades, Corey Westover, Emily Nell, Sameen Qadir and Gabrielle Oestreich for their assistance with quantitative data collection and Kristen Shellenberg for her contributions to the qualitative data collection and analysis. The authors would like to thank the clinics that participated and the women who shared their stories with them, and also the anonymous reviewers for their helpful comments.

Funding Funding for data collection and analysis were provided by an anonymous donor.

Competing interests None.

Provenance and peer review Not commissioned; externally peer reviewed.

\section{REFERENCES}

1 Finer LB, Frohwirth LF, Dauphinee LA, et al. Reasons U.S. women have abortions: quantitative and qualitative perspectives. Perspect Sex Reprod Health 2005;37:110-118.

2 DeNavas-Walt C, Proctor BD, Smith JC. Income, Poverty, and Health Insurance Coverage in the United States: 2008. US Census Bureau, Current Population Reports, P60-236. Washington, DC: US Government Printing Office, 2009.

3 Jones RK, Finer LB, Singh S. Characteristics of U.S. Abortion Patients, 2008. New York, NY: Guttmacher Institute, 2010.

4 Lichter DT, Qian Z, Mellott LM. Marriage or dissolution? Union transitions among poor cohabiting women. Demography 2006;43:223-240.

5 McLanahan S. Fragile families and the reproduction of poverty. Ann Am Acad Pol Soc Sci 2009;621:111-131.

6 Salganicoff A, Wyn R. Access to care for low-income women: the impact of Medicaid. J Health Care Poor Underserved 1999;10:453-467.

7 Field CA, Caetano R. Intimate partner violence in the U.S. general population: progress and future directions. J Interpers Violence 2005;20:463-469.

8 Jones RK, Moore AM, Frohwirth LF. Perceptions of male knowledge and support among U.S. women obtaining abortions. Womens Health Issues 2011;21:117-123.

9 Vest JR, Catlin TK, Chen JJ, et al. Multistate analysis of factors associated with intimate partner violence. Am J Prev Med 2002;22:156-164.

10 Frost JJ, Darroch JE. Factors associated with contraceptive choice and inconsistent method use, United States, 2004. Perspect Sex Reprod Health 2008;40:94-104.

11 Kost K, Singh S, Vaughan B, et al. Estimates of contraceptive failure from the 2002 National Survey of Family Growth. Contraception 2008;77:10-21.

12 Jones RK, Darroch JE, Henshaw SK. Contraceptive use among U.S. women having abortions in 2000-2001. Perspect Sex Reprod Health 2002;34:294-303.

13 Finer LB, Henshaw SK. Disparities in rates of unintended pregnancy in the United States, 1994 and 2001. Perspect Sex Reprod Health 2006;38:90-96.

14 Jones RK. How commonly do US abortion patients report attempts to self-induce? Am J Obstet Gynecol 2011;204: 23. e1-23.e4.

15 Moore AM, Frohwirth L, Blades N. What women want from abortion counseling in the United States: a qualitative study of abortion patients in 2008. Soc Work Health Care 2011;50: 424-442.

16 Moore AM, Frohwirth L, Miller E. Male reproductive control of women who have experienced intimate partner violence in the United States. Soc Sci Med 2010;70:1737-1744. 
17 Nelson HD, Nygren P, McInerney Y, et al. Screening women and elderly adults for family and intimate partner violence: a review of the evidence for the U.S. Preventive Services Task Force. Ann Intern Med 2004;140:387-396.

18 Dye JL. Fertility of American Women: 2008. US Census Bureau, Current Population Reports, P20-563. Washington, DC: Government Printing Office, 2010.

19 US Department of Labor and US Bureau of Labor Statistics. Women in the Labor Force: A Data Book. http://www.bls.gov/ cps/wlf-databook-2009.pdf [accessed 8 November 2011].
20 Kramer A, Lorenzon D, Mueller G. Prevalence of intimate partner violence and health implications for women using emergency departments and primary care clinics. Womens Health Issues 2004;14:19-29.

21 Roelens K, Verstraelen H, Van Egmond K, et al. Disclosure and health-seeking behaviour following intimate partner violence before and during pregnancy in Flanders, Belgium: a survey surveillance study. Eur J Obstet Gynecol Reprod Biol 2008;137:37-42. 